\title{
Correction to: Modeling of cutting forces in trochoidal milling with respect to wear-dependent topographic changes
}

\author{
Jim A. Bergmann ${ }^{1}\left[\right.$ (]) Nils Potthoff ${ }^{1} \cdot$ Tobias Rickhoff $^{1} \cdot$ Petra Wiederkehr $^{1}$
}

Published online: 11 June 2021

(c) (c) The Author(s) 2021

\section{Correction to: Production Engineering https://doi.org/10.1007/s11740-021-01060-4}

Due to technical problems, section 2.1 contained a misplaced symbol after publication of the paper. The description of workpiece dimensions has been corrected for the missing symbol.

Original article corrected.

Publisher's Note Springer Nature remains neutral with regard to jurisdictional claims in published maps and institutional affiliations.

The original article can be found online at https://doi.org/10.1007/ s11740-021-01060-4.

Jim A. Bergmann

jim.bergmann@tu-dortmund.de

1 Virtual Machining, TU Dortmund University,

Otto-Hahn-Straße 12, 44227 Dortmund, Germany 